\title{
A REPRESENTAÇÃO DO CAMPO LITERÁRIO NO CONTO ROMANCE NEGRO, DE RUBEM FONSECA
}

\author{
THE LITERARY FIELD REPRESENTATION IN THE \\ SHORT STORY ROMANCE NEGRO, BY RUBEM \\ FONSECA
}

\author{
Carine Maria Angst" \\ Pablo Lemos Berned ${ }^{* *}$
}

Resumo: Este trabalho tem por objetivo analisar o conto Romance Negro de Rubem Fonseca, a fim de identificar as estratégias utilizadas pelo texto ao estabelecer ligações com o sistema literário. Para isso, primeiramente, analisamos o conto pela perspectiva da análise estrutural da narrativa e, em um segundo momento, partimos para uma análise de fragmentos, de marcas discursivas e da presença de intertextos para relacioná-los com o funcionamento do campo literário. Os resultados sinalizam que as estratégias utilizadas demonstram que, para perceber essa relação dentro do texto, faz-se necessário um leitor que possua um alto conhecimento cultural e estético. Desta forma, é incorporado na própria estrutura do texto o tema abordado no conto de Fonseca.

Palavras-chaves: Análise Estrutural da Narrativa. Sistema Literário. Literatura Policial.

Abstract: The study aims to analyze Romance Negro by Rubem Fonseca, in order to identify the strategies used on the text when establishing connections with the literary system. For this, firstly, we analyze the short story on a structural perspective review of the narrative, in a second moment, we started the fragment analysis, discursive components and the presence of intertexts to relate them to the literary field functioning. The results imply that the strategies used indicate that, to understand this relationship within the text, it is necessary a reader who has high cultural and artistic knowledge. Thus, it is incorporated into the proper structure of the text the theme discussed on the short story by Fonseca.

KEYwORDs: Structural Analysis of the narrative. Literary system. Detective Stories.

\footnotetext{
"Graduada na Licenciatura em Letras; Português e Espanhol da Universidade Federal da Fronteira Sul, campus Cerro Largo. Email: carine.angst@gmail.com

* Doutor em Estudos de Literatura e professor de Teoria Literária e Literaturas de Língua Portuguesa na Universidade Federal da Fronteira Sul, campus Cerro Largo.Email: pablo.berned@uffs.edu.br
} 


\section{INTRODUÇÃO}

Este trabalho tem por objetivo apresentar a análise do conto Romance Negro de Rubem Fonseca. Romance Negro é um dos contos que constitui originalmente o livro Romance Negro e outras histórias, de Rubem Fonseca, publicado em 1992. Nele, o escritor aborda o caso do assassinato de um escritor (re)conhecido no campo literário que tem seu cargo e identidade tomados por um usurpador. No conto, percebemos que esse "novo" escritor dá continuidade às publicações do escritor, mantendo o vínculo com a editora dele e com o público que consome seus livros. Observamos, também, a relação que esse usurpador tem com sua consciência, uma vez que ele se torna outra pessoa, reconhecida no meio literário pelas obras que publica.

Em um primeiro momento, para a análise estrutural, analisamos categorias do texto literário que delimitaram os elementos essenciais da narrativa para que fosse possível estabelecer todo um sistema de significações e relações que o conto faz com outras narrativas e discursos. Assim, comprovamos que a organização do texto literário e seu conteúdo não são somente uma soma de proposições, mas que existem significados e representações imbricadas dentro do texto literário.

Em um segundo momento, partimos para uma análise dos próprios elementos que o texto e a estrutura do conto nos oferecem. Dessa forma, nesta etapa nos utilizamos de marcas discursivas, fragmentos do texto e a presença de intertextos para demonstrar as relações e conexões que comprovam a nossa tese de que o conto Romance Negro representa o funcionamento do sistema literário.
UMA PROPOSTA DE ANÁLISE ESTRUTURAL DO CONTO

Para a análise do conto Romance Negro, de Rubem Fonseca, utilizamos como referência teórica as propostas de Roland Barthes (2008) e Tzvetan Todorov (2008). A análise estrutural da narrativa terá como foco nos proporcionar um aprofundamento do texto literário, de suas funções e ações. Segundo Barthes (2008, p. 27), para conduzir uma análise estrutural é necessário, primeiramente, distinguir muitas instâncias de descrição e colocá-las sob a perspectiva hierárquica e/ ou integratória. Nessa perspectiva, o teórico propõe analisar o texto em partes (níveis), elencando as funções primárias e secundárias para que seja possível encontrar as significações ao longo do texto. A partir disso, formamos uma tabela para a análise do conto Romance Negro, e para constituí-lo, também usamos como base o texto As categorias da narrativa literária, de Tzvetan Todorov (2008).

Todorov (2008) indica a separação da análise em duas grandes categorias: a da narrativa como história e a da narrativa como discurso. Para sistematizar a tabela é importante frisar que nos baseamos na narrativa como história, isto é, ordenada cronologicamente, para apresentar as dependências encontradas ao longo da narrativa. Optamos por organizar a tabela desta forma, para estabelecer o denominador comum de cada coluna e as relações que se estabelecem entre eles. Posteriormente, analisaremos algumas das categorias como narrativa, visto que o texto é apresentado no nível do discurso.

Ao analisar estruturalmente o conto Romance Negro, observamos como se 
manifestam algumas dessas categorias no texto, principalmente na lógica das ações das personagens principais, que consiste em elencar e relacionar as ações da narrativa. Para isso, utilizamos um dos modelos de identificação das ações oferecido por Todorov (2008), chamado de modelo homológico. Esse modelo representa uma rede de relações paradigmáticas, estabelecendo assim, uma relação de dependência entre elementos que são encontrados e desencadeados na sucessão.

\section{O MODELO HOMOLÓGICO}

Diante das categorias de análise apresentada pelos autores, entendemos que as funções (BARTHES, 2008) - que equivalem a encontrar as correlações de fatos elencados no desencadear da história - e as ações (TODOROV, 2008) - que se fundamentam em catalogar e relacionar as ações da narrativa são equivalentes uma vez que se completam. Optamos, desta forma, usar as duas denominações (funções e ações) na exposição de nosso organograma. Essas categorias analisadas nos auxiliaram a estabelecer e conectar, de forma concisa, as relações apresentadas a seguir:

Quadro 1: Rede de revelações e consequências

continua

\begin{tabular}{|c|c|c|c|}
\hline \multicolumn{4}{|c|}{$\begin{array}{l}\text { Identificação das funções/ações da personagem principal de Romance Negro através do } \\
\text { modelo homológico }\end{array}$} \\
\hline \multirow{4}{*}{ 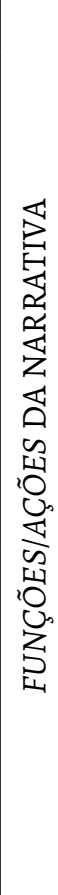 } & DESEJO/INTENÇÃO & REVELAÇÃO & REAÇÃO/CONSEQUÊNCIA \\
\hline & $\begin{array}{l}\text { - Landers submete o } \\
\text { livro O Quarto Fechado; } \\
\text { (p. 474)" }\end{array}$ & $\begin{array}{l}\text { - Clotilde recusa o livro; (p. } \\
\text { 474) }\end{array}$ & $\begin{array}{l}\text { - Landers vai até a cidade com a } \\
\text { pretensão de matar Clotilde; (p. 480) }\end{array}$ \\
\hline & (p. 473 até p. 480) & $\begin{array}{l}\text { - Landers marca um encontro } \\
\text { com Winner; (p. 474) } \\
\text { - Landers reconhece a } \\
\text { semelhança entre eles; (p. 475) } \\
\text { - Winner faz uma confidência } \\
\text { a Landers: que está acabado } \\
\text { e que não consegue mais } \\
\text { escrever; (p. 479) }\end{array}$ & $\begin{array}{l}\text { - Landers mata Winner e assume sua } \\
\text { identidade; (p. 481) }\end{array}$ \\
\hline & $\begin{array}{l}\text { - Landers e Clotilde se } \\
\text { encontram no trem; } \\
\text { (p. 486) } \\
\text { - Landers se encontra } \\
\text { com o amante de } \\
\text { Winner no trem e } \\
\text { marca um encontro } \\
\text { com ele; (p. 493) }\end{array}$ & $\begin{array}{l}\text { - Sandro percebe, no } \\
\text { encontro, que aquele não é o } \\
\text { verdadeiro Winner; (p. 495) }\end{array}$ & $\begin{array}{l}\text { - Landers mata o amante de Winner; } \\
\text { (p. 496) } \\
\text { - Landers comparece ao } 1^{\circ} \text { festival; (p. } \\
\text { 467); } \\
\text { - Landers namora e casa com Clotilde; } \\
\text { (p. 467) }\end{array}$ \\
\hline
\end{tabular}

"Optamos por inserir o número da página em que se encontram essas ações/funções com a finalidade de comprovar o que está sendo exposto. 
Quadro 1: Rede de revelações e consequências

continua

Identificação das funções/ações da personagem principal de Romance Negro através do modelo homológico

\begin{tabular}{|c|c|c|}
\hline $\begin{array}{l}\text { - Clotilde quer saber o } \\
\text { segredo de Landers/ } \\
\text { Winner; (p. 465; p. 466) }\end{array}$ & $\begin{array}{l}-2^{\circ} \text { festival: Landers/Winner } \\
\text { confessa que cometeu o } \\
\text { crime perfeito e dá o prazo de } \\
\text { três dias para que descubram } \\
\text { que crime é esse; (p. 470; p. } \\
\text { 471) }\end{array}$ & $\begin{array}{l}\text { - Landers/Winner resolve fazer uma } \\
\text { série de confissões sobre sua vida para } \\
\text { Clotilde; (p. 472) }\end{array}$ \\
\hline $\begin{array}{l}\text { - Insistência de Clotilde } \\
\text { para que Winner } \\
\text { comece a contar seu } \\
\text { segredo; (p. } 472 \text { ) }\end{array}$ & $\begin{array}{l}\text { - Landers confessa a Clotilde } \\
\text { que matou o verdadeiro Peter } \\
\text { Winner; (p. 472; p. 481) }\end{array}$ & $\begin{array}{l}\text { - Clotilde fica pasma e confusa ao } \\
\text { perceber que era verdade o que seu } \\
\text { marido estava contando, pois descobre } \\
\text { que o veneno que matou Winner } \\
\text { estava destinado a ela; (p. 480; p. } 481 \text { ) } \\
\text { - Clotilde fica revoltada pelo fato de } \\
\text { Landers não se arrepender do pecado } \\
\text { que cometeu, vai ao cinema, porque } \\
\text { está muito perturbada; (p. 484; p. 485) }\end{array}$ \\
\hline $\begin{array}{l}\text { - Quando Clotilde } \\
\text { volta do cinema, ouve } \\
\text { Landers gritando que } \\
\text { matou Peter Winner; } \\
\text { (p. 487) } \\
\text { - Clotilde fica } \\
\text { atordoada e começa } \\
\text { a fazer uma série de } \\
\text { revelações sobre a sua } \\
\text { vida; (p. 487; p. 488) } \\
\end{array}$ & $\begin{array}{l}\text { - Clotilde diz que Os crimes da } \\
\text { rua Morgue foi o conto mais } \\
\text { idiota que já leu, e, portanto, } \\
\text { não gosta de Edgar Allan Poe; } \\
\text { (p. 487; p. 488) }\end{array}$ & $\begin{array}{l}\text { - Landers fica chocado com o que } \\
\text { Clotilde acaba de contar; (p. 488) }\end{array}$ \\
\hline $\begin{array}{l}\text { - Clotilde expressa a } \\
\text { necessidade de contar } \\
\text { o seu segredo; (p. 488) }\end{array}$ & $\begin{array}{l}\text { - Clotilde diz que se casou } \\
\text { com Winner por causa do } \\
\text { livro Romance Negro; (p. 489); } \\
\text { - Landers conta que se casou } \\
\text { com Clotilde por causa de } \\
\text { seus ossos e de seu esqueleto; } \\
\text { (p.489) } \\
\text {-Clotilde revela seu segredo: } \\
\text { que tem } 50 \text { anos e não 40; (p. } \\
\text { 489; p. 490). }\end{array}$ & $\begin{array}{l}\text { - Após contarem seus segredos, os dois } \\
\text { tem um momento de intimidade; (p. } \\
490 \text { ) } \\
\text { - Landers participa de uma noite de } \\
\text { autógrafos e depois vai para o hotel, } \\
\text { enquanto que Clotilde vai a um jantar } \\
\text { do programa social; (p. 491) }\end{array}$ \\
\hline $\begin{array}{l}\text { - De madrugada, } \\
\text { Landers acorda } \\
\text { Clotilde e expressa a } \\
\text { necessidade de contar } \\
\text { outro segredo seu; (p. } \\
492 \text { ) }\end{array}$ & $\begin{array}{l}\text { - Landers confessa a Clotilde } \\
\text { que matou Sandro (amante } \\
\text { de Winner); (p. 496). }\end{array}$ & - Clotilde viaja para Paris; (p. 500) \\
\hline
\end{tabular}


Quadro 1: Rede de revelações e consequências

conclusão

\begin{tabular}{|c|c|c|c|}
\hline \multicolumn{4}{|c|}{$\begin{array}{l}\text { Identificação das funções/ações da personagem principal de Romance Negro através do } \\
\text { modelo homológico }\end{array}$} \\
\hline 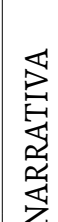 & $\begin{array}{l}\text { - Clotilde acredita } \\
\text { que Winner quer ser } \\
\text { descoberto e punido } \\
\text { pelo seu crime; (p. 497) }\end{array}$ & $\begin{array}{l}\text { - Clotilde liga para o Doutor } \\
\text { Prévost e o policial Papin } \\
\text { dizendo que seu marido } \\
\text { enlouqueceu; (p. } 498, \text { p. } 500 \text { ). }\end{array}$ & $\begin{array}{l}\text { - Landers recebe a visita do doutor } \\
\text { Prévost; (p.497); } \\
\text {-Landers quer se entregar, liga para o } \\
\text { policial Papin, mas ele não acredita em } \\
\text { nada que Landers fala; (p. 498; p. 499). }\end{array}$ \\
\hline 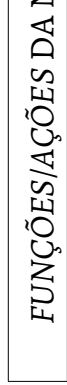 & $\begin{array}{l}\text { - Desejo de Landers } \\
\text { voltar a ser Landers, } \\
\text { de se entregar, mas } \\
\text { ninguém acredita nele; } \\
\text { (p. 500) } \\
\text { - Landers expressa } \\
\text { que tem um terceiro } \\
\text { segredo para contar } \\
\text { para Clotilde; (p. } 500 \text { ) }\end{array}$ & $\begin{array}{l}\text { - Landers confessa a Clotilde } \\
\text { que descobriu que Winner } \\
\text { era seu irmão gêmeo; (p. 501) }\end{array}$ & $\begin{array}{l}\text { - Landers é condenado a ser o irmão } \\
\text { que assassinou; (p. 501) } \\
\text { - Landers vai comer ostras às seis da } \\
\text { manhã em Grenoble. (p. 502) }\end{array}$ \\
\hline
\end{tabular}

Fonte: Elaborado pelos autores

Procuramos, conforme sugere o modelo homológico, um denominador comum das funções/ações do conto. Desta forma, a primeira coluna revela ações de desejo e de intenção, visto que através delas os protagonistas do conto demonstram possuir uma pretensão a ser alcançada. No caso, Landers submete seu livro para a editora com o objetivo de publicá-lo. O segundo quadro, referente a mesma coluna, está em branco, pois apresenta uma ruptura do texto. Não conseguimos identificar o porquê de Landers mudar de ideia e matar Winner, sendo que sua intenção era matar Clotilde, editora da Grasset. Podemos inferir, portanto, que o encontro com Winner foi uma tentativa de se aproximar de Clotilde, uma vez que Winner publicava seus livros pela editora Grasset. Assim percebemos também que Landers não tinha a pretensão de matar Winner, mas as circunstâncias auxiliaram para este desfecho.

Já a segunda coluna está atrelada, principalmente, às revelações que Landers/ Winner ${ }^{1}$ faz para sua amada Clotilde. É importante salientar, também, que esta coluna está encadeada à primeira e à terceira coluna. Quando Landers percebe a semelhança entre ele e Winner, essa revelação acaba desencadeando uma consequência que é a morte do escritor no conto. Desta forma, Landers acaba assumindo a identidade de Winner, escrevendo, publicando livros, participando de festivais e noites de autógrafos. Após usurpar a identidade do escritor, Landers tem a intenção de se aproximar de Clotilde Farouche

\footnotetext{
${ }^{1}$ Vamos utilizar a expressão Landers/Winner quando Landers estiver assumindo a identidade de Winner.
} 
no trem, o que acaba desencadeando a primeira coluna de desejo/intenção.

Na terceira coluna, denominada de reações e consequências, podemos perceber os resultados das revelações e das intenções dos protagonistas do conto. É o que acontece, por exemplo, quando Landers/Winner quer se entregar para a polícia e ninguém acredita nele em decorrência de Clotilde, anteriormente, ter comunicado ao policial Papin e ao doutor Prévost que seu marido havia surtado. Outro exemplo é a reação de Landers causada pela recusa de seu livro intitulado O Quarto Fechado, motivo que provocou sua ida até à cidade com o propósito de matar a então editora da Grasset, Clotilde Farouche.

Diante destas constatações, podemos verificar que o modelo homológico nos permitiu aprofundar o estudo do texto literário, uma vez que possibilita estabelecer ligações que estão imbricadas dentro do texto, tanto nos diálogos e nas observações do narrador quanto nos pensamentos e nas atitudes das personagens. Enfim, todos os encadeamentos da narrativa são elencados em um momento do conto e encontrados na sua sucessão, afirmando nossa assertiva de que as estratégias utilizadas no conto têm sempre uma significação.

\section{A CATEgORIA DO SER E PARECER NO TEXTO}

Consideramos ser importante explorar, no nível das personagens e suas relações, a contraposição entre a caracterização de cada personagem e a imagem que ela projeta de si própria para os outros. Nesse aspecto de ser e parecer, segundo Todorov (2008, p. 234), "cada ação pode primeiramente parecer amor, confidência, etc., mas pode, em segui$\mathrm{da}$, revelar-se como uma relação totalmente diferente", por isso, vamos identificar as mudanças de posturas entre as personagens principais do texto. Desta forma, associamos esse tópico ao relacionamento entre o usurpador do escritor Winner e sua esposa Clotilde.

Clotilde e Landers/Winner se conheceram no trem indo para o festival, acabaram se enamorando e no espaço de um mês se casaram. A relação deles era estável, até que Clotilde é abalada, dois anos depois, pelas confissões de seu amado Landers, quando descobre que ele matou o verdadeiro escritor Peter Winner. Primeiramente, Clotilde acredita que o escritor está flertando, mas percebe que a história é verdadeira quando Landers confessa que o veneno que matou Winner estava destinado a ela, porque recusou seu livro O quarto fechado. Essa suposição vai ser confirmada ao longo da narrativa, pois quando Winner conta seu primeiro segredo ambos estão nus, demonstrado pela expressão: "mas seu corpo nu está dizendo que é tudo verdade" (FONSECA, 2004, p. 480), o que faz com que Clotilde deixe de acreditar que Landers/Winner estava flertando, pelo fato de escritores gostarem de inventar histórias.

Neste instante, Clotilde sofre um choque de realidade. Na categoria do parecer, Clotilde demonstra amar Landers/Winner, no entanto, podemos perceber que no desenrolar da história, na categoria do ser, ela demonstra estar mais preocupada com o retorno financeiro da editora, advindos da publicação dos livros de seu marido. Assim, 
podemos supor que Clotilde projeta uma imagem na qual demonstra amar Winner, mas que na verdade pode ser caracterizada por um fingimento da própria editora para manter as relações de poder.

Isso é compreendido quando Clotilde toma a atitude de ligar para o policial Papin e o doutor Prévost dizendo que Winner estava completamente surtado (mesmo sabendo que isso não era verdade), estabilizando assim sua carreira e de seu marido. Outra confissão feita por ela, e que comprova essa hipótese, é a de que se casou com Landers/ Winner por causa do livro Romance Negro (FONSECA, 2004, p. 489). Identificamos, assim, um interesse tanto profissional quanto financeiro na atitude de Clotilde se casar com Landers/Winner.

Desta maneira, podemos concluir que Clotilde, tendo acesso tanto à vida privada quanto à profissional de Landers/Winner, busca status para si mesma e para a sua editora. Já, em relação à postura de Landers, é perceptível a categoria do parecer, uma vez que ele usurpa o lugar de um escritor reconhecido na sociedade literária, dando continuidade às suas publicações, usufruindo de sua fama e dinheiro. Depois de suas revelações, podemos perceber nitidamente quem é Landers (ser), mesmo parecendo ser Winner, o escritor.

\section{A NARRATIVA COMO DISCURSO}

No conto Romance Negro, durante a narrativa, há uma progressão e regressão contínuas do discurso, como podemos perceber pela escolha dos subtítulos. O narrador começa a história descrevendo um momento de intimidade entre Winner e Clotilde e, no primeiro subtítulo, Dois anos antes, relata a participação de Winner no festival realizado há dois anos, quando lança o livro Romance Negro. Em Agora, novamente em Grenoble, a narrativa volta ao festival em Grenoble (dois anos depois), quando Winner/Landers confessa ter cometido o crime perfeito, no qual ele dá o prazo de três dias para que descubram que crime é esse. Após essa confissão, seguem-se novas revelações, conforme os subtítulos restantes do conto: Primeiro segredo de Peter Winner ou John Landers; O segredo de Clotilde; O segundo segredo de John Landers; e, por fim, $A$ cilada dos deuses: terceiro e último segredo de John Landers.

Desde a epígrafe é antecipada a ideia de encadeamento (TODOROV, 2008), em que se justapõem diferentes planos narrativos: All that we see or seem/Is but a dream within a dream... que pode ser traduzida por: "Tudo aquilo que vemos ou nos parece/ Nada mais é do que um sonho dentro de um sonho...". Esta referência a Edgar Allan Poe, "um sonho dentro de um sonho", ressalta o entrelaçamento da trajetória das duas personagens: a do escritor Winner e a do professor de Literatura, Landers.

Desta forma, quando a narração está em terceira pessoa, temos o primeiro plano da história, em que se acredita que Landers é Winner, e no qual são representados e narrados seus papeis como escritor e marido. Assim, podemos verificar que o encadeamento de duas histórias é marcado justamente pela alternância de vozes na narração do conto, como veremos a seguir. 
Além do narrador do primeiro plano, no conto também percebemos a presença e alternância da voz narrativa, ou seja, o próprio personagem principal e também sua esposa como narradores ocasionais da história. Como narradores, Landers e Clotilde narram em primeira pessoa, em um segundo plano da narrativa, pois revelam seus segredos um ao outro. Verificamos que há uma predominância dessa forma de narração no conto, identificado no texto pelo uso de duas aspas e o uso de uma aspa para marcar os diálogos ocorridos nas narrações, como nos exemplos: “'É sua', eu disse, deixando a revista nas suas mãos e virando-lhes as costas [...]"(FONSECA, 2004, p. 475) e "Falsifiquei tudo. Me custou uma fortuna. Eu tinha medo que você não se casasse comigo [...]" (FONSECA, 2004, p. 489). Além do uso das aspas, podemos perceber marcas discursivas como "é sua", "eu tinha medo", para marcar esse tipo de narração.

Nessa perspectiva, no segundo plano do conto, em que relata a história da usurpação, temos uma autorrepresentação da função de escritor no conto. Dessa maneira, percebemos que o conto apresenta uma estrutura em mise-en-abyme, que consiste em ordenar "uma sequência $B$ que está encaixada em uma sequência A" (DALLENBACH, 1991, p. 65) ou, em outras palavras, uma narrativa que contém outras narrativas dentro de si, mantendo o contato entre o narrador e o narratário.

Além disso, no conto, podemos identificar que, em boa parte do discurso, o narrador sabe tanto quanto as personagens, como percebido no trecho a seguir: "Enquanto morde o cotovelo de Clotilde, Landers pensa nos seus outros segredos, que ele considera tão terríveis ou ainda mais atrozes do que o desvendado; mas acha conveniente deixar essas revelações para outra oportunidade (FONSECA, 2004, p. 490)." Diante disso, podemos constatar que o narrador tem acesso a todos os pensamentos e ao passado de Landers, uma vez que revela que os outros segredos de Landers são "tão terríveis ou ainda mais atrozes", fazendo uma comparação ao primeiro segredo que Landers conta à Clotilde. O narrador, neste caso, também relata a pretensão de Landers contar os seus outros segredos para Clotilde, mas em outra oportunidade, como pode ser percebido no trecho destacado pelas expressões "Landers pensa", "ele considera" e "acha conveniente".

Já em outros fragmentos, mas com menor frequência, o narrador parece saber menos que as personagens, pois narra somente o que está sendo observado: "Clotilde sai da cama, senta-se na poltrona do quarto, de boca aberta, pasma (FONSECA, 2004, p. 480)." Nesse caso, o narrador demonstra ser apenas aquele que narra o que está sendo representado no conto. Esse tipo de narração aparece no conto principalmente para subsidiar os diálogos entre as personagens, marcadas pelo emprego de verbos dicendi, o que justifica a falta de conhecimento ou o acesso por parte do narrador ao que as personagens estão pensando e pretendendo.

Diante da proposta de análise estrutural, constatamos que as estratégias utilizadas no texto, que foram aprofundadas com o estudo do modelo homológico, com as relações entre as personagens estudadas pela categoria do ser e do parecer, e da análise da 
narrativa como discurso, permitiram-nos estabelecer evidências de que o conto Romance Negro representa o funcionamento do campo literário.

REPRESENTAÇÃO DO CAMPO LITERÁRIO NO CONTO ROMANCE NEGRO

Após realizarmos a análise estrutural da narrativa, que permitiu aprofundar o estudo do texto literário, nesta seção vamos analisar a representação do funcionamento do sistema literário presente no conto Romance Negro. Inicialmente, vamos comparar os dois escritores que são apresentados, Winner e Landers, para demonstrar como é representado o campo literário no conto. Em um segundo momento, apresentaremos algumas considerações sobre o subcampo da literatura policial, já que Landers e Winner eram considerados escritores de romance negro. No terceiro momento, apresentaremos duas formas diferenciadas de consagração que Winner e Landers buscavam dentro do sistema literário. Na quarta subseção, vamos analisar a representação dos critérios de aceitação e circulação dos livros. Na quinta subseção, analisaremos as estruturas de legitimação e poder do campo e, por último, verificaremos a representação de autor e leitor feitas no conto.

SEMELHANÇAS E DIFERENÇAS ENTRE John LANDers E Peter Winner: DOIS ESCRITORES DE ROMANCE POLICIAL

As semelhanças mencionadas pelo narrador Landers entre os dois escritores no conto são respectivamente: ambos serem professores de literatura, "americanos auto-exilados na Europa", "filhos adotivos", admiradores de Edgar Allan Poe, "Era parecidíssimo comigo, a mesma estatura, o mesmo rosto longo, o mesmo queixo fino" e, por fim, uma descoberta tardia de Landers e a última confissão que faz a Clotilde de que "Winner era meu irmão gêmeo” (FONSECA, 2004, pp. $473,474,475)$. Esses fragmentos retirados do texto comprovam que Landers e Winner tinham realmente muito em comum, tanto psicologicamente como fisicamente. Já o fato de ninguém ter percebido a troca, além do amante Sandro Morelli, também pode ser relacionado à circunstância de Winner não gostar de aparecer em público, o que será explorado mais tarde.

Já as diferenças que foram relatadas, também pelo narrador Landers: "O verdadeiro Winner, ao contrário de mim, até então um perdedor, era um escritor que merecia seu nome, coberto de fama, glória e dinheiro..." (FONSECA, 2004, p. 473). Outra comparação feita refere-se ao físico dos dois: "Eu usava óculos e ele não; quando tirou o chapéu para cumprimentar-me, notei que era um pouco mais calvo do que eu [...] gestos sutilmente efeminados" (FONSECA, 2004, p. 475). Constatamos que as diferenças físicas não eram significativas, o que corrobora com o fato de Landers descobrir que Winner era seu irmão gêmeo e de ninguém ter percebido a usurpação, exceto o amante da vítima.

Quando Landers narra esses fatos, percebemos que há a repetição da palavra "coincidência” (FONSECA, 2004, pp. 474, $475,476)$, o que pode ter cooperado para que Landers decida matar Winner, pois 
anteriormente não mencionava ter esta pretensão. Destacamos e relacionamos ao sistema literário a circunstância de Winner ser reconhecido como escritor, enquanto que Landers se considerava um "perdedor", já que teve seu livro $O$ quarto fechado recusado pela editora Grasset. Além disso, o nome Winner, traduzido para o português, significa vencedor, o que realça uma estratégia implícita do texto para reforçar esta diferença entre os dois.

Há, no conto, uma representação do que Williams (2009) chama de luta entre classes hegemônicas e emergentes do sistema literário, sendo que a emergente representa grupos que tentam chegar ao poder, ou seja, que contêm valores, experiências e significados que surgem continuamente na vida social e que estão em disputa de espaço para serem aceitos. Já a cultura hegemônica é aquela que tem valores centrais, efetivos e dominantes e influenciam valores e pensamentos de toda a sociedade. Essa luta entre classes hegemônica e emergente é retratada, por exemplo, pelo seguinte trecho no conto: "Eu disse a Winner que escrevia ficção e gostaria de ser um escritor profissional, mas que até então jamais fora publicado." (FONSECA, 2004, p. 477). Constatamos que Winner é um escritor consagrado, pois é valorizado enquanto tal. Já Landers representa o escritor emergente, que deseja ascender à consagração, mas que para isso, primeiro, precisa ter seus livros publicados.

O sistema literário, enquanto um microcosmo social, possui vários subcampos em seu interior. Um destes subcampos tem como referência os artistas consagrados que escrevem obras que constituem o cânone, destinadas para uma menor parte da população, principalmente professores de literatura, apoiados pela investigação universitária. Assim como existem subcampos que fazem referência a artistas em busca do sucesso comercial que escrevem para um público mais amplo e que procuram vender as obras para ter retorno financeiro (BOURDIEU, 2011).

Identificamos no conto esta luta entre estes campos de produção do sistema literário, representados respectivamente pelos dois escritores: Peter Winner e John Landers. Para isso, primeiramente fazem-se necessárias algumas considerações referentes ao romance policial, uma vez que os escritores são classificados a este subcampo de produção artística e cultural.

\section{O SUBCAMPO DA LITERATURA POLICIAL}

Sandra Lúcia Reimão (1983), na introdução de seu livro $O$ que é romance policial, já menciona que esse tipo de literatura foi um dos mais vendidos de todos os tempos. Isso aconteceu em decorrência do surgimento dos jornais populares no século XIX, em que narrativas policiais geravam prazer e atração em seus leitores. Essa apreciação por parte dos leitores também se relaciona ao surgimento da polícia no século XIX, em que primeiro há uma aceitação, mas, logo após, a população começará a ficar insatisfeita com essa nova instituição.

Segundo Reimão (1983), Edgar Allan Poe foi o criador da narrativa policial, com a publicação de Os crimes da rua Morgue em 1841, tornando-se o exemplo mais expressivo da narrativa de enigma. Desta forma, o romance 
de enigma comandou a narrativa policial por muito tempo, contribuindo para essa tradição escritores como Dashiell Hammet, Conan Doyle, Agatha Cristie, constituindo o eixo principal do romance policial.

Dessa forma, surgem os primeiros grandes detetives que não são policiais, dando ênfase positivista no raciocínio e na lógica. Surge então o criminoso, como inimigo, e o detetive, que representa o bem. Depois disso, vão surgindo vários tipos de narrativas policiais como de suspense, de enigma e o romance negro.

Para Reimão (1983) e Boileau-Narcejac (1991), o criador do romance negro foi Dashiell Hammett e um seguidor significativo foi Raymond Chander. Esse tipo de narrativa surgiu justamente para aquele leitor que já estava enfastiado com o romance de enigma clássico, uma vez que o romance negro apresenta personagens com visões de mundo diferentes, ambientes violentos, imoralidades e nem sempre o detetive como solucionador do caso.

Em razão disso, julgamos importante classificar o subcampo da literatura de enigma e os tipos de narrativas que surgiram depois dele. Para Koethe (1994, p. 123), “a novela de detetive é uma hermenêutica popularizada”, pois são gêneros mais consumidos pela população, como forma de entretenimento. Para o teórico, a novela de detetive é um produto típico das grandes cidades, resultado da industrialização capitalista. Já o romance negro, nas palavras de Narcejac (1991), libertou um ingrediente popular trazendo uma nova forma de escrita, para que seja consumida pelo povo, trazendo consigo um grande retorno financeiro.

Portanto, podemos concluir que as narrativas policiais são menos consagradas quando comparadas a literatura canônica, já que não apresentam um reconhecido grau estético, uma vez que são consumidas pela população de massa. Assim, a literatura policial é desvalorizada, já que é feita para leitores iniciantes. No conto, mais especificadamente no festival em Grenoble, e entre a conversa de Winner e Landers, identificamos que há a representação e a exposição sobre origens e consagração do romance policial dentro do campo literário. É por isso que no conto são feitas referências aos escritores de obras policiais no debate em Grenoble, assim como durante a conversa de Winner e Landers. São mencionados nomes como Edgar Allan Poe, Conan Doyle, Emile Gaboriau, Edgar Wallace, Hammet, citando alguns de seus detetives e algumas obras. Neste caso, a presença de estratégias intertextuais (SAMOYAULT, 2008) no conto reforça a ideia da representação do sistema literário, mais especificadamente do subcampo da literatura policial, ao expor várias citações de obras, de personagens e de escritores, relacionando-os sempre com o texto e a história narrada.

Além disso, percebemos que, no conto, Billé, moderador do debate, não faz menção à existência de uma escola francesa de romance negro como forma de provocar Landers/ Winner, pois ele acreditava que apesar dos franceses serem os "principais exegetas, hermeneutas do gênero" (FONSECA, 2004, p. 469), não criaram uma tradição no roman noir como os americanos Poe e Hammett. O 
excerto destacado a seguir comprova essa tese: "Quando publiquei meu terceiro romance pela Grasset', disse Winner, 'os franceses incluíram-me no clube [...]" (FONSECA, 2004, p. 481). Essa menção feita ao clube por Landers/Winner está ligada ao fato de os franceses pós-guerra terem publicado, em 1945, pela editora Gallimard, romances policiais e de mistério com o título La Série Noir (MISSE, 2013).

Como pode ser percebido no conto, o próprio título Romance Negro já representa um tipo de narrativa policial. O título também faz referência explícita ao título do livro que Landers/Winner publicou, percebida pela transcrição do jornal: "Estará presente ao Festival de Grenoble o famoso escritor americano Peter Winner. Seu último livro $O$ farsante confirma sua atual fase de esplendor, iniciada com Romance negro (FONSECA, 2004, p. 465). Nesse fragmento, percebemos que a fama do escritor foi iniciada com a publicação do livro Romance Negro, no qual trata do paranoico obsessivo Kramer, fugitivo de um asilo de loucos (FONSECA, 2004, p. 468).

Outra ligação que podemos estabelecer com o título é a própria ruptura do que pode ser chamado de romance negro, pois Landers/Winner, no festival em Grenoble, inverte os dados: "Acabamos de dizer que o romance negro se caracteriza pela existência de um crime, com uma vítima que se sabe logo quem é; e um criminoso, desconhecido; e um detetive, que afinal descobre a identidade desse criminoso. Assim, não existe o crime perfeito" (FONSECA, 2004, p. 470). Após essa suposição, Landers/Winner afirma existir o crime perfeito tanto na vida real como na literatura. Diz que o criminoso é ele e lança o enigma:

Numa história policial, permitam-me repetir, sabemos da ocorrência do crime, conhecemos a vítima, mas não sabemos quem é o criminoso. Neste crime perfeito todos saberão logo quem é o criminoso e terão que descobrir qual é o crime e quem é a vítima. Eu apenas mudei um dos dados do teorema (FONSECA, 2004, p. 470).

Diante disso, mais uma possiblidade de relacionar o título do conto é representada pela ruptura que Landers/Winner faz com o que pode ser definido por romance negro na literatura. Nesse sentido, faz-se necessária a representação das condições de produção e recepção do romance policial e a sua consagração dentro do campo literário.

\section{CONSAgRAÇõES DOS ESCRITORES E SUA} RELAÇÃo COM O CAMPO LITERÁRIO

No conto Romance Negro, percebemos que, mesmo Landers e Winner serem considerados escritores de romance negro, eles buscavam diferentes tipos de consagração dentro do campo literário. Isso pode ser entendido pelas comparações referentes à personalidade e escrita do velho Winner e do novo Winner (Landers):

Era um novo Winner, pensei, sim, um novo Winner, os críticos tinham razão, você havia conseguido a façanha de escrever um romance diferente dos outros. Aos quarenta anos, depois de um romance fracassado, deixava para trás fórmulas que manipula com grande mestria e criava uma coisa 
inteiramente nova. Eu devia ter desconfiado de que o homem não era o mesmo (FONSECA, 2004, p. 488).

É através destas comparações e até críticas feitas a Winner, que constatamos algumas mudanças de postura em relação aos dois escritores. $O$ trecho destacado demonstra que o verdadeiro Winner procurava seguir o modelo tradicional de consagração, já seu usurpador tentou criar algo novo e foi muito prestigiado economicamente e muito bem recebido pelo público consumidor do subcampo da literatura policial.

Para comprovar nossa hipótese, elencamos alguns excertos que comprovam que Winner não buscava reconhecimento como escritor: "Winner não gostava de dar entrevistas, nem de ser fotografado; tinha horror de caviar e de Mozart; [...]”. Isso era praticamente tudo o que se sabia sobre esse escritor famoso (FONSECA, 2004, p. 474). Outro fragmento que evidencia que Winner não procurava reconhecimento: “[...] na verdade, não me apresentarei pessoalmente, alguém lerá para mim o que pretendo dizer" [...] (FONSECA, 2004, p. 478). Dessa forma, relacionamos a circunstância do escritor não gostar de aparecer em público ao fato de não buscar fama dentro do subcampo da literatura policial.

Outro trecho que evidencia que Winner não buscava o reconhecimento do público consumidor de seus livros era o fato de ele não considerar a sua literatura como sendo toda composta de romances policiais: "Para mostrar o tipo de critério adotado pelos franceses, entre os convidados deste ano estão alguns escritores que não costumam ser identificados como autores de romances policiais [...]. Creio que parte ponderável da minha literatura também não se enquadra nas normas do gênero (FONSECA, 2004, p. 481)". Assim sendo, os trechos corroboram com a hipótese de que Winner representa e se aproxima do campo de produção artístico, que procura reconhecimento estético (MUKAROVSKY, 1981), mesmo que inserido no subcampo da literatura policial.

Tanto que, no conto, após Winner ter sua identidade, vida pública e privada usurpados, começa-se a perceber uma ruptura quanto a sua posição como escritor:

Seu comparecimento ao festival, há dois anos, criou uma comoção no mundo literário. Até então Winner não dava entrevistas, não comparecia a congressos, festividades, solenidades, acontecimentos sociais, e não havia dinheiro que o convencesse a aparecer na TV (FONSECA, 2004, p. 467).

Nesse trecho, é possível identificar que o usurpador de Winner almejava ter fama e dinheiro, ou seja, ser reconhecido dentro do subcampo da literatura policial. Verificamos, também, que Landers e Winner, por serem professores de literatura, conheciam o cânone literário e, portanto, se posicionaram de maneira diferente perante ele.

Constatamos que essa representação no conto remete à oposição entre arte e dinheiro, que estruturam o campo do poder, sendo reproduzidos no interior do campo literário, na forma de oposição entre arte 'pura', simbolicamente dominante, mas economicamente dominada, e a arte comercial que almeja grandes lucros e consagração burguesa 
(BOURDIEU, 2011). Dessa forma, podemos averiguar que Winner se aproxima da arte "pura", enquanto que Landers representa a arte "comercial" que, por sua vez, prioriza o retorno econômico.

Critérios de aceitação, publicação E CIRCULAÇÃO DOS LIVROS DENTRO DO SISTEMA LITERÁRIO

Relacionamos ao funcionamento do sistema literário o critério de aceitação e publicação dos livros, que competem aos agentes de consagração do microcosmo social. Podemos perceber a representação do sistema de legitimação do campo social no Romance Negro quando Clotilde recusa o livro O quarto fechado de Landers, e posteriormente justifica sua recusa: "Mas na suposição de que Romance Negro era de Winner tive paciência para superar as estranhezas, as rupturas, as anormalidades, os desusos, as singularidades" (FONSECA, 2004, p. 488). Isso demonstra outra particularidade do funcionamento do microcosmo social, uma vez que um escritor que já é consagrado e conhecido pelo público, tem a possibilidade de vender mais livros. Já um artista que o público não conhece representa uma tentativa de publicação e venda, portanto sofre o risco de não dar retorno financeiro para sua editora.

Em Romance Negro, identificamos pela voz do narrador, uma grande crítica a esse campo de produção, por visar acima de tudo, grandes lucros:

A Grasset, que publicava um monte de mediocridades, não queria publicar o seu romance. Na verdade, não havia mais editoras independentes, todas integravam grandes conglomerados financeiros controlados por estúpidos sef made men que haviam ganho dinheiro de maneira selvagem e inescrupulosa e encaravam o livro como uma mercadoria qualquer (FONSECA, 2004, p. 486).

Em razão disso, temos que levar em consideração que o público consumidor também se transforma com o passar do tempo. Para isso, Umberto Eco (2004) assegura que se tentou modificar, com o tempo, o gosto e a linguagem dos livros para serem recebidos pela mass media (cultura de massa). Sabemos que a cultura erudita sempre foi apropriada por uma elite, e que a cultura de massa é destinada ao consumo do povo com um linguajar de fácil acesso. A expressão cultura de massa ou mass media, ainda segundo Eco (2004), é decorrente da globalização, que tenta homogeneizar o povo e tornar descartáveis as produções, tendo em vista sempre o lucro.

Desta forma, com o público consumindo, é sempre necessário que se produza algo novo, que fuja do tradicional, que seja algo efêmero e que tenha um grande poder lucrativo. Ainda mais na contemporaneidade, em que a publicidade, advindas da expansão dos meios de comunicação (TV, rádio, internet), faz com que se consumam produtos pensados pela classe economicamente dominadora. Essa forma de produção representa uma forma de manter a classe hegemônica no poder para que se tenha o domínio sobre a população (WILLIAMS, 2009) e uma forma permanente de consumo.

No conto, Clotilde trabalha na editora Grasset e exerce a função de ler os livros e fazer um julgamento para ver quais podem 
ser publicados, tanto que recusou, a obra de seu atual marido. Consequentemente, ela é uma representante da instância de legitimação do microcosmo social por qualificar os livros que merecem, sob seu juízo, serem publicados. Clotilde e sua editora representam, desta forma, o sistema capitalista, que visa sempre grandes lucros com suas publicações. Como já mencionado, esse sistema de legitimação procura livros (best-sellers) que sejam consumidos, principalmente, pela população de massa.

Isso pode ser percebido pela sugestão de mudanças de títulos que Clotilde fazia para o verdadeiro Winner: "[...] Você sabe como gosto de dar sugestões sobre os títulos dos seus livros... Lembra quantas cartas tive de escrever até você aceitar mudar o título do último?" (FONSECA, 2004, p. 486). Enfim, podemos perceber uma estratégia da representação do campo de produção e consumo representado em Romance Negro. Em virtude disso, Clotilde trabalha na editora e, por isso, precisa pensar em títulos e capas que sejam bem chamativas para que o leitor se sinta instigado a ler o livro e, principalmente, adquiri-lo.

REPRESENTAÇÕES DE LEITOR E AUTOR NO CONTO

Verificamos que o texto valoriza o papel do leitor no texto Romance Negro. Para isso, vamos analisar os seis leitores que são apresentados no texto: Winner, Landers, Clotilde, P. D. James, James Elroy e Willy Voos. Em primeiro lugar, Landers e Winner, além de serem escritores, professores de literatura e admiradores de Edgar Allan Poe, se envolveram em uma conversa sobre o romance policial (FONSECA, 2004, p. 477), demonstrando ter um vasto conhecimento sobre as obras literárias associadas a este gênero e oriundas dele. O narrador Landers ainda relata que "enquanto bebíamos tagarelávamos sobre o nosso ídolo como dois professores que éramos tentando demonstrar que um era mais erudito do que o outro (FONSECA, 2004, p. 477)". Isso demonstra que eles eram grandes conhecedores de obras consagradas e de grandes escritores e pensadores da literatura:

Em outras palavras, os "bons" escritores não têm, muitas vezes, outros leitores a não ser os outros "bons" escritores, seus concorrentes, e é necessário cada vez mais tempo para que as obras, antes esotéricas, encontrem um público que lhes imponha as normas de sua própria avaliação. (COMPAGNON, 2010, p. 234)

Nesse sentido, podemos destacar que os bons escritores "entendem" as obras consagradas, uma vez que se utilizam do conhecimento que elas proporcionam para escrever suas próprias obras. Podemos relacionar o fato com o que Compagnon (2010) considera ser uma obra com alto valor estético, e que necessariamente precisa de um leitor que sempre esteve em contato com esse tipo de obras, evidenciando ter uma grande carga cultural para entendê-las.

Em outras palavras, para Bourdieu (1996), o crítico literário e os leitores de obras canônicas tem um olhar de leitura mais refinado, pois são iniciados neste campo de produção artística. Esses leitores são educados 
para ler adequadamente/esteticamente as obras denominadas consagradas que são lançadas no campo de produção canônica.

Os outros leitores retratados no conto são os escritores D. James, James Elroy e Willy Voos, que participam do debate (com Landers/Winner) no festival em Grenoble. Debatem sobre o romance policial, romance negro enquanto Landers/Winner anima o debate afirmando existir e ter cometido o crime perfeito. Esses debatedores e escritores se enquadram ao conceito de leitor-modelo (ECO, 2011), no qual o leitor busca descobrir o que o texto, independentemente do propósito do autor, de fato diz, fazendo movimentos cooperativos para chegar a uma significação. Esses escritores demonstram, ao longo do debate, ter um vasto conhecimento, principalmente sobre os escritores que se enquadram e escreveram sobre as histórias policiais, sendo exemplos de leitores modelos desse gênero.

Clotilde, por último, como instância legitimadora da Grasset, também é uma representante de leitor no conto. Porém, ela expressa odiar o conto Os crimes da rua Morgue, o que não acontece com os demais leitores representados no texto. O conto também faz menção sobre a importância do leitor, expressas pela narradora Clotilde, que pode ser demonstrado pelo seguinte trecho: "Me apaixonei pelo livro. E depois, o mesmo aconteceu com os críticos e com o público (FONSECA, 2004, p. 488)". Apresentamos desta maneira uma representação do valor que os críticos e os leitores têm dentro do subcampo de produção da literatura policial, visto que almejam sempre o consumo dos livros publicados.

Outro momento em que é possível a intromissão de leitores no conto, é no debate em Grenoble, em que um dos leitores tenta desvendar o enigma que Winner propôs no festival: "Os últimos livros de Winner são totalmente diferentes dos anteriores. A personalidade de Winner, hoje, é diferente da personalidade de Winner dois anos atrás. Você, Peter Winner, matou Peter Winner" (FONSECA, 2004, p. 471). Desta maneira, podemos propor duas hipóteses de leitura, utilizadas por Fonseca (2004), neste caso: ou o leitor percebeu a diferença de estilo na escrita dos dois e inferiu que a pessoa não poderia ser a mesma, ou ele estava utilizando-se de uma metáfora para dizer que o escritor conseguiu mudar seu estilo de escrita. Neste caso, temos novamente um leitor do romance policial, e que pode ser considerado um exemplo de leitor-modelo, já que chega perto da solução do enigma. Enfim, com a análise apresentada, podemos constatar que o escritor Rubem Fonseca utilizou e relacionou vários elementos para realizar a representação do funcionamento do campo literário dentro do conto Romance Negro.

\section{CONSIDERAÇÕES FINAIS}

Diante do exposto, constatamos que a análise estrutural da narrativa proposta pelos teóricos Barthes (2008) e Todorov (2008) nos permitiu verificar que as estratégias do texto não são isentas de significação, proporcionando aprofundar o estudo do texto literário. Dessa forma, constatamos que a análise estrutural nos concedeu verificar que o conto 
Romance Negro incorpora uma representação do funcionamento do campo literário.

Essa representação do sistema literário imbricada no texto viabilizou comprovar que as estratégias explícitas e implícitas empregadas por Rubem Fonseca (2004) carregam uma valoração a respeito do texto literário. Desse modo, a leitura do conto possibilita afirmar que o texto literário, considerado literatura e pertencente ao cânone, necessita de um leitor que já esteja habituado e teve contato a estes níveis de leitura desde muito cedo. Assim como, foram criadas estruturas que pudessem ser consumidas pela população de massa, e, que apresentam um enredo de mais fácil compreensão.

Com tudo isso, podemos asseverar que tanto os leitores de alta literatura quanto os de best-sellers conseguiriam usufruir o conto escrito por Fonseca (2004), afinal não é tão complexo para ser entendido. É, possível, porém, que somente o leitor com o olho refinado e com um alto conhecimento cultural e estético perceber o que está além do enredo da história, atribuindo sentido ao que está implícito e representado nela. Desta forma, é incorporado na própria estrutura do texto o tema abordado no conto de Fonseca.

\section{REFERÊNCIAS}

BARTHES, Roland. Introdução à análise estrutural da narrativa. In: BARTHES, Roland et. al. Análise Estrutural da Narrativa. Tradução Maria Zélia Barbosa Pinto. 5 ed. Petrópolis, RJ: Vozes, 2008.

. Da obra ao texto. In: O rumor da língua. Tradução Mário Laranjeira, Andréa Stahel M. da Silva. 2 ed. São Paulo: Martins Fontes, 2004
BOILEAU-NARCEJAC. O romance policial "noir". In: $O$ romance policial. Tradução de Valter Kehdi. São Paulo: Ática, 1991.

BOURDIEU, Pierre. A gênese histórica da estética pura. In: As Regras da Arte: gênese e estrutura do campo literário. 2 ed. São Paulo: Companhia das Letras, 2005.

. Por uma ciência das obras. In: Razões práticas: sobre a teoria da ação. Tradução Mariza Corrêa. 11 ed. Campinas, SP: Papirus, 2011.

COMPAGNON, Antoine. Ovalor. In: O demônio da Teoria: Literatura e senso comum. Trad. Cleonice Paes Barreto Mourão e Consuelo Fortes Santiago. Belo Horizonte: Editora UFMG, 2010.

DALLENBACH, Lucien. Hacia una tipología del relato especular. In: El relato especular. Traducción de Ramón Buenaventura. Madrid: Visor distribuicione, 1991.

ECO, Umberto. Cultura de Massa e "Níveis" de Cultura. In: Apocalípticos e Integrados. 6 ed. São Paulo: Perspectiva, 2004. O leitor-modelo. In: Lector in fabula: a cooperação interpretativa nos textos narrativos. Tradução Attílio Cancin. São Paulo: Perspectiva, 2011.

FONSECA, Rubem. Romance negro. In: 64 contos/Rubem Fonseca. São Paulo: Companhia das letras, 2004.

KOETHE, Flávio Rene. Arte e trivialidade. In: A narrativa trivial. Brasília: Editora Universidade de Brasília, 1994.

MISSE, Michel. Chandler no Cinema Noir: algumas reflexões sobre "A simples arte de matar". Sociologias, Porto Alegre, ano 15, n. 34, p. 140-154, set./dez. 2013.

MUKAROVSKY, Jan. Função, norma e valor estético como factos sociais. In: Escritos 
sobre estética e semiótica da arte. Tradução de Manuel Ruas. Lisboa: Editorial Estampa, Lda, 1981.

POE, Edgar Allan. Assassinatos na rua Morgue. In: Assassinatos na rua Morgue. Tradução de William Lagos. Porto Alegre: L\&PM, 2013.

REIMÃO, Vera Lúcia. O que é romance policial. 2 ed. São Paulo: editora Brasiliense, 1983.

SAMOYAULT, Tiphiane. A intertextualidade. Tradução de Sandra Nitrini. São Paulo: editora Hucitec, 2008.

TODOROV, Tzvetan. As categorias da narrativa literária. In: BARTHES, Roland et al. Análise Estrutural da Narrativa. Tradução Maria Zélia Barbosa Pinto. 5 ed. Petrópolis, RJ: Vozes, 2008. WILLIAMS, Raymond. Teoría cultural. In: Marxismo y literatura. Buenos Aires: Las Cuarenta, 2009.

Recebido para publicação em 20 nov. 2015. Aceito para publicação em 02 maio 2016. 